\title{
Pedagogia Hospitalar no Hospital Municipal de Tangará da Serra - MT
}

\author{
Maria Sonia Silva ${ }^{1}$; Lilian Rebecca Pereira ${ }^{2}$; Mauricio Dallastra ${ }^{3}$; Luiz Eduardo Brescovit ${ }^{4}$
}

Resumo: A pesquisa foi realizada na brinquedoteca do Hospital Municipal de Tangará da Serra - MT, com objetivo de compreender as aplicações de práticas pedagógicas proporcionadas pelo profissional Pedagogo na ala pediátrica do Hospital Municipal. Os aspectos metodológicos foram pautados na abordagem qualitativa, através da coleta de dados por meio de entrevistas, com perguntas abertas, direcionadas as crianças hospitalizadas e seus acompanhantes. As perguntas foram gravadas com um celular, após a coleta as entrevistas passaram pelo processo de transcrição respeitando na íntegra a linguagem de cada um dos entrevistados. O resultado do trabalho pedagógico indicou melhora do aspecto social e possibilidade de internação entre crianças e acompanhantes na ala pediátrica, gerando alegria possibilitando a criança um pouco de divertimento no período de internação. As atividades foram vistas como um momento de distração para os internos e seus acompanhantes, proporcionando a criança um lugar mais prazeroso no decorrer do tratamento através da pedagogia hospitalar.

Palavras-Chave: Educação. Criança. Hospital. Lúdico.

\section{Hospital Pedagogy at the Municipal Hospital of Tangará da Serra - MT}

Abstract: The survey was conducted in the playroom of the Municipal Hospital of Tangara da Serra - MT, in order to understand the applications of pedagogical practices provided by professional educator in the pediatric ward of the Municipal Hospital. Methodological aspects were based on a qualitative approach, by collecting data through interviews with open questions, directed hospitalized children and their companions. The questions were recorded with a cell phone, after collecting the interviews went through the transcription process respecting fully the language of each of the respondents. The result of pedagogical work indicated improved social aspect and the possibility of hospitalization among children and caregivers in the pediatric ward, generating joy enabling the child a little fun during hospitalization. The activities were seen as a moment of distraction to the internal accompanying them, providing the child a more pleasurable place during treatment through the hospital pedagogy.

Key-Words: Education. Child. Hospital. Playfu

\section{Introdução}

A abordagem proposta para realização deste trabalho foi desenvolver atividades pedagógicas com crianças internadas no Hospital Municipal de Tangará da Serra - MT,

\footnotetext{
${ }^{1}$ Graduada em Pedagogia pela Faculdade FAEST, no ano de 2016.

${ }^{2}$ Professora Mestre em Ciências Ambientais pela UNEMAT - Universidade Estadual do Estado de Mato Grosso, no ano de 2009.

${ }^{3}$ Arquiteto e Urbanista graduado pela Universidade Paranaense, no ano de 2012 e especialista em Iluminação e Design de Interiores pelo Instituto de Pós Graduação IPOG no ano de 2016.

${ }^{4}$ Professor graduado em Educação Física Bacharelado e Licenciatura pela Faculdade Assis Gurgacz no ano de 2009, com especialização em Educação Infantil e anos iniciais no ano de 2009, Pedagogo pela Faculdade FAEST, no ano de 2016.
}

573 Id on Line Rev. Mult. Psic. V.12, N. 39. 2018 - ISSN 1981-1179 Edição eletrônica em http://idonline.emnuvens.com.br/id 
trabalho este que é realizado pelo profissional pedagogo, acreditando assim que a pedagogia hospitalar terá grande contribuição quanto aos pacientes internados no espaço hospitalar.

Denota-se que as atividades pedagógicas no ambiente hospitalar podem tornar o ambiente mais acolhedor e humanizado, possibilitando as crianças e seus acompanhantes uma melhor relação afetiva e social, gerando um avanço significativo para o processo de recuperação dos mesmos.

Atividades pedagógicas realizadas no ambiente hospitalar podem ajudar no processo de recuperação da criança que se encontra hospitalizada, o pedagogo pode contribuir com a autoestima da criança, visto que mesmo doente a criança não perde o prazer em brincar, dessa forma desenvolvendo atividades parecidas com o que realizava no seu cotidiano.

Quando se fala da importância das práticas pedagógicas, deve-se levar em conta as brincadeiras lúdicas, como os jogos pedagógicos, contação de história, leituras em livros, o brincar no ambiente hospitalar é magnifico.

Este trabalho teve como objetivo registar as reações do universo infantil e do adulto, entendendo que o espaço da brinquedoteca seja um lugar para acontecer momentos de socialização com outras crianças e seus acompanhantes, assim possibilitando um ambiente acolhedor que poderá resgatar a autoestima e a alegria de cada criança.

\section{Fundamentação teórica}

\section{A pedagogia hospitalar}

O profissional pedagogo tem grande importância no ambiente hospitalar, mas ainda é pouco reconhecido. O pedagogo pode atuar em diversas áreas, inclusive no hospital, trabalhando com crianças afastadas de suas atividades escolares, e com atividades não escolares na ala da recreação.

Franco e Selau (2011 p. 182) destacam que, [...] O pedagogo é um profissional que tem formação de educador e que, por meio de atividades pedagógicas, pode intervir no processo de ensino e aprendizagem da criança hospitalizada [...].

Dessa forma é importante visar que o trabalho do pedagogo no ambiente hospitalar, não se trata de uma simples brincadeira, que pode ser realizado por uma simples pessoa, esse 
trabalho visa a formação que o pedagogo tem para trabalhar com crianças de várias faixas etárias.

Wolf (2007) ressalta que [...] a prática do pedagogo se dará através das variadas atividades lúdicas e recreativas como a arte de contar histórias, brincadeiras, jogos, dramatização, desenhos e pinturas [...].

A pedagogia hospitalar vem crescendo significativamente nos grandes centros. O profissional que atua na pedagogia hospitalar, tem a formação condizente ao espaço que hoje são considerados não formais para a educação, assim podendo o educador trabalhar no processo de ensino e aprendizagem, afirmando as prerrogativas do curso de Pedagogia, por estarem preparados para atuar em qualquer ambiente que através de seu currículo proporcione aprendizado. Cabendo aí dentro de sua formação, estimular e motivar as crianças enfermas, trabalhando com atividades lúdicas aliviando as tensões geradas pela doença para objetivar um resultado eficaz e positivo, suscitando momentos de esquecimento das enfermidades através delas.

Carmo (2008), afirma também que, através do brincar, a criança, quando em contato com os instrumentos hospitalares dos médicos (estetoscópio por exemplo), passa a não ter medos e receios, fazendo com que sua estadia hospitalar e também com apoio lúdico dos pedagogos, percebam um ambiente mais humanizado e familiar.

De acordo com Ceccim e Fonseca apud Franco e Salau (2011 p. 178), [...] independente do tempo de permanência da criança no hospital, o atendimento [...] ajuda a criança a se desvincular das restrições deste ambiente e pode ter um significado importante para o processo de desenvolvimento e aprendizagem.

\section{O universo infantil e a hospitalização}

Quando a criança é saudável ela mostra-se ativa, brinca o tempo todo, se exercita e, quando se depara em um ambiente hospitalar é privada das brincadeiras no período de internação, o mesmo vai desencadear alguns desconfortos como, estresse, choros, tendências a depressão e isso vai contribuir para a não aceitação do tratamento. As atividades pedagógicas se fazem importantes no ambiente hospitalar, uma vez que a criança está hospitalizada ela 
precisa de cuidados e atenção, visto que sempre haverá rejeição da mesma nos tratamentos, sendo assim o ambiente hospitalar acaba tornando-se um espaço cansativo e melancólico.

Para Wuo apud Pereira (2007 p. 25) destaca que, o profissional de recreação deve estar sempre à procura de ativar o estado de ânimo, estimulando e interagindo na área hospitalar, ser ainda mais sensível e atento as possibilidades individuais de cada ser que ali se apresente.

No período de internação a criança sofre com o afastamento do seu convívio familiar, causando alguns sofrimentos no decorrer do tratamento, a criança se depara com um ambiente totalmente diferente daquele que é acostumado no seu dia-a-dia, então a importância de desvelar os benefícios que a atividade pedagógica vai proporcionar para o mesmo no decorrer de sua recuperação, fazendo com que a criança se sinta motivada, tornando um ambiente agradável onde o mesmo não vai se sentir tão distante daquele ambiente que estava acostumado, o momento das atividades proporcionará alguns benefícios à criança. Sendo assim a criança não vai se sentir tão distante de sua realidade.

Conforme Furtado apud Pereira (2007 p. 24), relata que a participação da mãe no brincar do filho, além de reforçar o relacionamento entre ambos, também é fonte de lazer para a acompanhante já que a mesma tem poucas oportunidades de distração no hospital.

Quando a criança está doente, a essência do querer viver e aproveitar, não é abalada pelo medo da doença. A brincadeira é um grande aliado para elas, ela é intrínseca. Sendo assim o brincar vai possibilitar um avanço significativo no tratamento, aliado ao espaço diferenciado que se pode propor, ambos acabam se tornando um lugar prazeroso permitindo que a crianças se sintam acolhidas e felizes.

Segundo Wuo apud Pereira (2007 p. 19), a recreação com caráter ativo, cria no interno mecanismo de criatividade, este poderá dançar, rir, correr, pular e jogar com sua doença, transformando o ser doente em um ser alegre, expressivo e criativo.

Ressalta-se também a importância do espaço, no âmbito arquitetônico, proporcionar condições agradáveis de conforto, seja ergonômico ou visual. Neste contexto faz-se necessário a concepção de ambientes que promovam e estimulem a ludicidade para que, através do profissional da pedagogia, seja corretamente explorado e assim possa contribuir para o processo do tratamento destes indivíduos. Oliveira (2012) afirma que a atmosfera hospitalar deve ser humanizada e, para tal, deve ser adequada à faixa etária dos pacientes, lúdico (explorados através das cores, texturas, figuras e objetos) além de possuir espaços de 
lazer e recreação e ergonomia, tanto para os pacientes quanto para os visitantes e profissionais.

\section{A importância das atividades}

No período da internação muitas crianças se afastam das atividades escolares, dessa forma ressalta-se a importância de trabalhar com o lúdico no ambiente hospitalar, contribuindo assim, para que a criança não fique totalmente afastada das suas vivencias escolares, pois terá apoio pedagógico nessa fase, e também para aquelas crianças que se encontram em curto prazo de internação, ajudando na autoestima, no desenvolvimento, no ambiente e na socialização.

Para Cunha apud Abreu e Fagundes (2010 p. 34)

Toda criança merece ter garantido o seu direito de brincar. Brincando elas estão prestando atenção, estão concentradas, desenvolvendo habilidades, raciocinando, trabalhando o prazer sem necessidade de castigo ou prêmios. Estão desenvolvendo o habito de se ocupar de forma adequada. O brincar é fundamental, porque, como dizia Piaget, a recompensada ação deve estar na própria ação, no prazer de executála. Essa frase é capaz de mudar o mundo. Se fizemos as coisas pelo simples prazer de fazê-las, estamos fazendo com o coração, com o sentimento de alegria por estar executando determinada atividade. É o que acontece com o brincar, e por isso é tão importante. O brincar ensina á criança essa relação.

Desta forma, pode-se observar a importância das atividades pedagógicas lúdicas no ambiente hospitalar, promove o desenvolvimento da criança, proporcionando momentos de alegria e brincadeiras que de alguma forma vão contribuir para uma melhora no período de internação.

Carmo apud Abreu e Fagundes (2010, p. 33) ainda afirma que a criança hospitalizada ao brincar expressa seu sentimento e se recupera mais rapidamente, ele destaca também que toda criança tem direita de brincar mesmo quando hospitalizada.

Diante da afirmativa do autor, as atividades pedagógicas/lúdicas seriam uma forma de a criança esquecer um instante oque está passando e vivenciado, em um ambiente tão distante do seu vínculo familiar, essas brincadeiras seria uma forma menos dolorosos, fazendo que a criança aceitasse o seu período de internação de uma forma mais descontraído, ajudando no melhoramento do seu tratamento.

De acordo com Segaspini apud Dantas et al (2009 p, 65): 
A doença e a hospitalização desencadeiam uma série de sensações nas crianças, como traumas, estresse, medo, angústia, solidão, ansiedade, retraimento, hostilidade, frustação, depressão, insegurança, apatia, irritação e sofrimento. Além disso, podem provocar alterações no desenvolvimento físico, motor, social, psicológico e emocional.

Diante dessa afirmação, o brincar no ambiente hospitalar proporciona a criança alegria e prazer, diminuindo as angústias que o mesmo sente nesse período, por meio dos brinquedos e das brincadeiras que vai amenizar um pouco essas tensões que o ambiente causa.

\section{Metodologia}

\section{Natureza da pesquisa}

A presente pesquisa teve cunho qualitativo. Segundo Dalfovo, Lana e Silveira (2008) a pesquisa qualitativa é aquela que busca analisar as informações coletadas pelo pesquisador sem a participação de estatísticas ou dados numéricos. Cassel e Symom (1994) destacam as principais características qualitativas de uma investigação:

[...] ênfase na subjetividade ao invés de na objetividade: aceita-se a busca de objetividade é um tanto quanto inadequada, já que o foco de interesse é justamente a perspectiva dos participantes. [...] a interação entre pesquisador e pesquisado é fundamental, razão pela qual se exige do pesquisador diversos aperfeiçoamentos, principalmente as técnicas comunicacionais. [...] (p. 127-129, apud DALFOVO; LANA; SILVERIO, 2008 p. 11).

\section{Local de estudo e caracterização dos participantes}

A pesquisa foi realizada na brinquedoteca do Hospital Municipal de Tangará da Serra - MT. Participaram das atividades pedagógicas, as crianças internadas na ala pediátrica que se encontravam em condições clinicas aptas a participar das intervenções pedagógicas, totalizando 9 crianças, sendo 5 meninos e 4 meninas, na faixa etária de 8 meses a 10 anos com ou sem acompanhante.

\section{Coleta de dados}


A pesquisa foi realizada no ano de 2016, mês de agosto, através de intervenções pedagógicas três (03) vezes por semana com duração de 1 hora e meia, totalizando 10 horas e meia. As atividades realizadas se remeteram a jogos pedagógicos, como jogo da memória, quebra cabeça, jogo da velha, tangran, pinturas em desenhos impressos e leituras de livrinhos.

Para cada criança foi anotado um cadastro constando sua identificação, sexo, idade e situação clínico atual, assim podendo saber os principais diagnósticos dos internos.

Para a realização da intervenção foi solicitado o preenchimento de um termo de consentimento livre e esclarecido (apêndice I), para as crianças e seus acompanhes constando a autorização para a liberdade de participar ou se retirar das atividades quando fosse de sua vontade.

A entrevista foi realizada através de um questionário com perguntas abertas, direcionadas para as crianças e seus acompanhantes, a saber: 1. Como você se sente fazendo atividades pedagógicas no hospital? (criança); 2. Quais atividades você mais gostou de realizar? Por quê? (criança); 3. O que você achou das atividades pedagógicas no ambiente hospitalar? (acompanhante).

As perguntas foram gravadas com um celular, após a coleta as entrevistas passaram pelo processo de transcrição respeitando na íntegra a linguagem de cada um dos entrevistados.

$\mathrm{Na}$ transcrição foram utilizados pseudônimos para preservar a identidade dos participantes e o emprego das letras (C) para as crianças e a letra (A) para os acompanhantes para assim diferenciá-los.

\section{Análise dos dados}

Os dados registrados na entrevista e no caderno de campo foram categorizados, ou seja, distribuídos em forma de categorias que foram mencionados nos resultados e discussão, podendo assim formar os significados em relação às respostas das crianças e dos acompanhantes. 


\section{Resultados e discussão}

\section{Perfil clínico dos participantes internados na ala pediátrica}

O perfil clínico das crianças que participaram das atividades pedagógicas no Hospital Municipal foram principalmente quadros ligados a: infecção de urina, problemas nos rins, acidente doméstico, broncopneumonia e com maior frequência pneumonia, enfermidades não graves, fazendo com que o paciente não permanece por vários dias no hospital.

\section{A criança hospitalizada e o brincar}

Durante o período que foi realizado as atividades e as entrevistas, pode-se observar a importância de cada brincadeira, todas as crianças que ali se encontravam sentia o prazer em realizar as atividades, cada um com seu jeito de brincar, uns queriam jogos, outras queira pintar desenhos, assim podendo ver a felicidade e a alegria que as brincadeiras proporcionavam para elas ali naquele momento de socialização entre eles.

\section{Como você se sente fazendo atividades pedagógicas no hospital?}

Fala de algumas crianças que participaram das atividades.

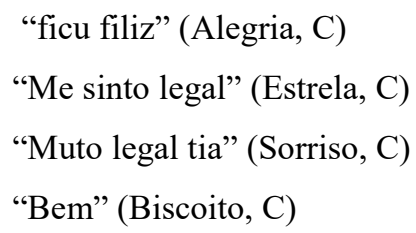

Para Barbosa apud Pereira (2007 p. 21), em seu estudo mostra que as brincadeiras seduzem a crianças distraindo-as de tal forma, "fazendo-as se sentir em um outro mundo, acabando por esquecer de seus problemas e dificuldades".

No decorrer da pesquisa pode ser observado o aspecto social no ambiente, as crianças e seus acompanhantes se envolviam nas brincadeiras proporcionando interação entre eles.

De acordo com Azevedo (2004. P. 52): 


\begin{abstract}
A brinquedoteca é um espaço criado para favorecer a brincadeira. É um espaço onde as crianças (e os adultos) vão para brincar livremente, com todo o estimulo e manifestação de suas potencialidades e necessidades lúdicas. Muitos brinquedos e matérias permitem a expressão da criatividade.
\end{abstract}

Carmo (2008) defende o espaço brinquedoteca em hospitais como essencial para o desenvolvimento, tratamento e aprendizado da criança e reforça a necessidade de ter, em ambientes desta tipologia, a presença de profissionais capacitados para promover o melhor aproveitamento dos recursos disponíveis no local.

Dava para ver a felicidade das crianças quando estavam brincando, os acompanhantes também pode compartilhar desse momento. Dessa forma contribuindo com o aspecto emocional das crianças internas.

$\mathrm{Na}$ fala a seguir relata-se a participação de uma criança interna, que mesmo estando em um ambiente hospitalar tinha vontade para brincar:

Bia participou das atividades 3 dias da minha pesquisa, ela ficava em um quarto individual, na porta tinha um vidro que permitiam ver quem passasse na frente, quando ela me via ficava toda animada querendo ir logo para a brinquedoteca, chegava lá logo pedia para brincar com ela de jogo da memória, dava para ver que ela estava se divertindo, ainda mais quando ela ganhava.

O tempo de internação para muitos foram curto devido o diagnostico, sendo assim tendo pouco contato, no decorrer da pesquisa teve 2 crianças que tiveram um maior período de tratamento, podendo participar mais das atividades, uns até queriam ser entrevistado novamente.

\title{
Olhares dos acompanhantes sobre a prática pedagógica hospitalar
}

A atividade pedagógica hospitalar teve grande aceitação por parte dos acompanhantes, muitos pronunciaram que esse espaço da brinquedoteca é de grande relevância para as crianças que se encontra em processo de hospitalização.

Dessa forma, as atividades foram vistas como um momento de divertimento para as crianças e acompanhantes. O acompanhante também teve participação no questionário 
aplicado com a seguinte pergunta: $\mathbf{O}$ que você achou das atividades pedagógicas no ambiente hospitalar?

A seguir apresenta-se os relatos:

\begin{abstract}
“Olha é interessante, nu questão da desenvolvimento da criança que se trabalha com as varias idades né e a questão da a criança ela tira aquela mente de hospitalar que fica só remédio é só tratando da criança né ela desvirtua a mente né então muda a questão da brincadeira o acompanhamento de vocês é bom" (Cravo, A).

"É importante, é bom pra criança desenvolve um pouco e ela parada estressa né fica nervosa só dentro da sala com medicamento é interessante gostei” (Flor, A).
\end{abstract}

Os estímulos cognitivos foram desenvolvidos nos momentos das atividades, onde eles puderam brincar com oque e na hora que queria através das atividades pedagógicas as crianças trabalharam o seu raciocínio, fugindo um pouco daquele ambiente que ali estava.

A influência do brincar no hospital é de grande relevância, pois proporciona de forma concreta, momentos de alegria, enfatizando que a criança esquece a sua enfermidade por um momento, através da pesquisa, enfatizado como a fala abaixo:

\footnotetext{
"Muito bom gostei bom que distrai a criança né fica o tempo todo dentro do quarto fechado, é bom que ajuda a desenvolve fica mais alegre, mais contente a hora passa mais rápido, muito bom" (Rosa, A).

"A achei uma boa ideia, eu achei que ajuda no tratamento das crianças que anima eles" (Orquídea, A).
}

De acordo com Santos apud Azevedo (2004, p. 58), a principal função educacional da brinquedoteca é a valorização da atividade lúdica, o que consequentemente, traz satisfação ás necessidades afetivas das crianças. Quando se fala em ambiente hospitalar deve-se pensar no emocional da criança hospitalizada, pois através das brincadeiras ela vai desenvolver o lado afetivo, assim buscando um melhor rendimento no tratamento.

\title{
Reação da criança no ambiente hospitalar
}

Durante o período de internação foi registrado varias situações positivas geradas através das brincadeiras, a alegria no rosto das crianças a felicidade em estar brincando, sair do quarto e ir para brinquedoteca para eles era um momento de interação com as outras crianças, isso fez com que a brincadeira tornasse prazerosa. 
Segundo Silva apud Azevedo (2004, p. 55) a brinquedoteca é um espaço preparado para estimular a criança a brincar, a desenvolver a socialização, cognição, afetividade [...].

Através das brincadeiras eles expressam oque está sentindo ali naquele momento, como pode ver na fala através da pergunta. Quais atividades você mais gostou de realizar? Por quê?

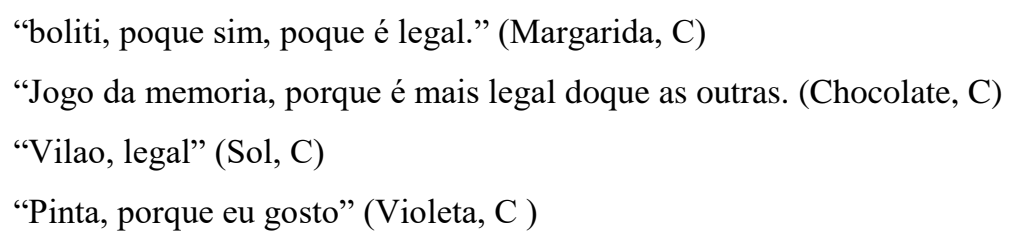

Para Kishimoto (2005 p. 24), quando brinca a criança toma certa distancia da vida cotidiana, entra no mundo imaginário [...]. No ambiente pode ser observado uma relação de comunicação entre eles, o jogo de duplas contribuiu para uma relação de socialização no ambiente. Dessa forma ocorreu a interação das crianças. As atividades mais solicitadas pelas por elas foram: jogo da memoria, boliche e pinturas em desenhos impressos.

\section{Considerações finais}

Tendo em vista as analises realizadas no decorrer desse trabalho, perceber-se a contribuição das obras utilizadas, tendo em vista que só teve a agregar na pesquisa feita, usando o embasamento teórico para escrever sobre as atividades/lúdicas pedagógicas que são de grande importância, pois a criança quando brinca ela se desliga dos seus pensamentos ruins, as brincadeiras vai amenizar um pouco o período em que estiver no ambiente hospitalar, essas atividades podem ser visto como uma forma de que a criança se distrai um pouco nesse ambiente.

As atividades foram benéficas, ajudando no estado emocional das crianças internadas e seus acompanhantes, através das brincadeiras percebe-se a interação entre eles, a satisfação de estar brincando, o sorriso no rosto.

O brincar no hospital envolveu as crianças e seus acompanhantes, através das diversas brincadeiras, jogos, e leituras, fez com que esquecesse por um momento o período 
que estava passando, os estímulos cognitivos foram desenvolvidos nos momentos dos jogos e brincadeiras, assim possibilitando um momento de interação entre eles.

Sendo assim, as atividades dentro do hospital proporcionou uma vivência harmoniosa entre criança e acompanhante, quando a criança está hospitalizada, surge algumas restrições, a mudança de ambiente gera medo e angustia, o brincar despertou na criança um momento alegre, no entanto as atividades desenvolverem os aspectos cognitivo, social, afetivo, assim possibilitando uma melhora no período em que a criança estivesse em processo de hospitalização.

\section{Referências}

AZEVEDO, Antonia Cristina Peluso de Brinquedoteca no diagnóstico e intervenção em dificuldades escolares. Campinas, SP: Editora Alínea, 2004.

ABREU, Simone Aparecida Kraus; FAGUNDES, Elizabeth Macedo. Brinquedoteca hospitalar: sua influencia na recuperação da criança hospitalizada. In: Voos Revista Polidisciplinar Eletrônica da Faculdade de Guairacá. v. 02, n. 1, 2010, p. 33-49: <http://www.revistavoos.com.br/seer/index.php/voos/article/viewArticle/73>. Acesso em: 30 de set. de 2015 .

CARMO, A. A brinquedoteca hospitalar: uma intervenção positiva para criança hospitalizada. Monografia (Departamento de Educação do Centro de Referência em Distúrbios de Aprendizagem). São Paulo: 2008. Disponível em http://www.crda.com.br/tccdoc/3.pdf> Acesso em 29 de set. de 2016.

DALFOVO, Michael Samir; LANA, Rogério; SILVEIRA, Amélia. Métodos quantitativos e qualitativos: um resgate teórico. In: Revista Interdisciplinar Cientifica Aplicada. Blumenau. v. 2, n. 4, 2008, p. 01-13. Disponível em: <http://www.unisc.br/portal/upload/ com_arquivo/metodos_quantitativos_e_qualitativos_um_resgate_teorico.pdf $>$. Acesso em: 06 de out. de 2015.

DANTAS et al. A contribuição do lazer no processo de hospitalização: Um estudo de caso sobre os benefícios do projeto risoterapia. In: Disponível e m:<https://seer.ufmg.br/index.php/licere/article/viewFile/578/467>. Acesso em: 14 de nov. de 2015.

FRANCO, Priscila de Fátima Pereira; SELAU Bento. A atuação do Pedagogo no ambiente hospitalar: algumas reflexões. In: Revista Liberato, Novo Hamburgo, v. 12, n. 18, p. 107 - 
206, jul./dez. 201, disponível em <http://www.liberato.com.br/sites/default/ files/arquivos/Revista_SIER/v.\%2012,\%20n.\%2018\%20(2011)/7.a\%20atua\%E7\%E3o\%20do $\% 20$ pedagogo\%20no\%20ambiente\%20hospitalar.pdf> Acesso em 27 de set. de 2016.

KISHIMOTO, Tizuko Morchida. Jogo, brinquedo, brincadeira e a educação. $8^{\circ}$ ed. - São Paulo: Cortez, 2005.

OLIVEIRA, Juliana Simili de. Humanização em saúde: arquitetura em enfermarias pediátricas. Dissertação (Mestrado em Ambiente Construído) - Universidade Federal de Juiz de Fora, Juiz de Fora, 2012, disponível em <https://www.ufjf.br/ambienteconstruido/files/2012/03/DISSERTA\%C3\%87\%C3\%83OJuliana-Simili-de-Oliveira-2012.pdf> Acesso em 29 de set. de 2016.

PEREIRA, Lilian Rebecca. Recreação Hospitalar. Tangará da Serra-MT: 2007.

UTZIG, Gilmar, Manual para Elaboração e Normatização de Trabalhos Acadêmicos. Disponível em <http://uniserratga.com.br/site_uniserra/wp-content/uploads/2012/09/ManualTrabalhos-Cient\%C3\%ADficos-2016-FAEST.pdf> Acesso em 5 de abril de 2016.

WOLF, Rosangela Abreu do Prado, Pedagogia Hospitalar: A Prática do Pedagogo em Instituição não Escolar. Disponível em<http://177.101.17.124/index.php/ conexao/article/view/3836/2714> Acesso em 19 de Set. de 2016.

\section{Como citar este artigo (Formato ABNT):}

SILVA, Maria Sônia; PEREIRA, Lilian Rebecca; DALLASTRA, Mauricio; BRESCOVIT, Luiz Eduardo. Pedagogia Hospitalar no Hospital Municipal de Tangará da Serra - MT. Id on Line Revista Multidisciplinar e de Psicologia, 2018, vol.12, n.39, p.573-585. ISSN: 1981-1179.

Recebido: 15.01.2018

Aceito: 15.01.2018 